\title{
The effect of oxidation state on the viscosity of melts in the system $\mathrm{Na}_{2} \mathrm{O}-\mathrm{FeO}-\mathrm{Fe}_{2} \mathrm{O}_{3}-\mathrm{SiO}_{2}$
}

\author{
DONALD B. DINGWELL* and DAVID VIRGO \\ Geophysical Laboratory, Carnegie Institution of Washington, 2801 Upton Street NW, Washington, DC 20008, U.S.A.
}

(Received August 7, 1986; accepted in revised form November 4, 1986)

\begin{abstract}
The viscosities of two melts in the system $\mathrm{Na}_{2} \mathrm{O}-\mathrm{FeO}-\mathrm{Fe}_{2} \mathrm{O}_{3}-\mathrm{SiO}_{2}$ have been measured as a function of oxidation state. The experiments were conducted by concentric-cylinder viscometry, on melts equilibrated with $\mathrm{CO} / \mathrm{CO}_{2}$ gas mixtures in a vertical tube, gas-mixing furnace. Viscosity determinations were made during stepwise reduction and oxidation of the melts. ${ }^{37} \mathrm{Fe}$ Mössbauer spectra were obtained on quenched melt samples recovered during the viscometry experiments. In addition, a series of loop fusion experiments were performed at calibrated $f \mathrm{O}_{2}$ values in order to relate viscosity determinations directly to $\mathrm{fO}_{2}$.

The viscosities of acmite and NS4F40 (Na-rich and Si-poor relative to acmite) melts decrease with reduction of $\mathrm{Fe}$ in the melts, as nonlinear functions of $\mathrm{Fe}^{3+} / \Sigma \mathrm{Fe}$, yielding a region of viscosity invariance at moderate to low values of $\mathrm{Fe}^{3+} / \Sigma \mathrm{Fe}(<0.4)$. The ${ }^{57} \mathrm{Fe}$ Mössbauer spectra of quenched melts as a function of $\mathrm{Fe}^{3+} / \Sigma \mathrm{Fe}$ indicate the presence of one (network-modifying) ferrous species and two ferric species with ferric iron acting dominantly as a network-former in oxidized melts and dominantly as a network-modifier in reduced melts.

The presence of two ferric iron species produces a minimum in the degree of polymerization of the melt at intermediate values of $\mathrm{Fe}^{3+} / \Sigma \mathrm{Fe}$ : the region of viscosity invariance corresponds to this minimum. If viscosity is positively correlated with polymerization for all values of $\mathrm{Fe}^{3+} / \Sigma \mathrm{Fe}$ then the viscosity of very reduced melts will increase with reduction, as the melt polymerizes.

The effect of oxidation state on viscosity is large and illustrates that ferric iron should be considered as a separate component in calculation schemes for estimating the viscosity of natural magmas.
\end{abstract}

\section{INTRODUCTION}

A CHANGE OF the chemical potential of oxygen during igneous petrogenesis will, in general, result in a change in the oxidation state of the igneous melt expressed as the ferric-ferrous ratio. Accordingly, geochemists have long recognized the usefulness of ferric-ferrous ratios of minerals and melts for inferring redox trends in igneous rock series.

More recently, the influence of the ferric-ferrous ratio on the physical properties of silicate melts has received attention (e.g. viscosity, CUKIERMAN and UHLMANN, 1974; density, Mo et al., 1982). Viscosity is a physical property of silicate melts that is central to the discussion of mass transfer within or between phases. Processes that involve mass transfer are, in turn, the fundamental mechanisms of igneous differentiation.

Despite the observation that iron is a major constituent of igneous melts, current information regarding the effect of redox equilibria on the viscosity of ironbearing melts is scarce. This scarcity of information was noted by BOTTINGA and WEILL (1972). These authors were forced to neglect the possible effects of oxidation state on viscosity in the development of their now widely used calculation scheme for estimating the viscosity of igneous melts. Since 1972, a number of studies of the relationship between the viscosity and the oxidation state of silicate melt have been reported. Unfortunately, several factors, including the techniques employed and the compositions investigated, have

* Present address: Earth and Planetary Sciences, Erindale College, University of Toronto, Mississauga, Ontario, Canada, LSL 1 C6. limited the precision of some of these data and complicate comparison and generalization of the results. Clearly, a more systematic study is required.

Recently, the structural role of iron in silicate melts has received substantial attention and a number of structural probes have been applied to the determination of iron coordination in silicate melts (e.g. EXAFS, BROWN et al., 1979; XRDF, HENDERSON $e t$ al., 1984; ${ }^{57} \mathrm{Fe}$ Mössbauer spectroscopy, VIRGO and MYSEN, 1985; Raman spectroscopy, MYSEN et al., 1985a; optical absorption and luminescence spectroscopy, Fox et al., 1982; ESCA, GoldMAN, 1986).

The results of previous viscometry studies indicate that the effect of oxidation state on the viscosity of certain Fe-bearing silicate melts is large and the results of previous structural studies provide evidence of differing structural roles for ferric and ferrous iron. On the basis of the premise that melt structure directly influences melt viscosity, it would appear timely to conduct a series of investigations of both the viscosity and the coordination of iron in some simple silicate melt systems to clarify the relationship between viscosity and important melt structural parameters (such as polymerization). The present study, conducted in the system $\mathrm{Na}_{2} \mathrm{O}-\mathrm{FeO}-\mathrm{Fe}_{2} \mathrm{O}_{3}-\mathrm{SiO}_{2}$, is such an investigation.

The present study is unique in several ways. For the first time (to the best of the authors' knowledge), the viscosity of a silicate melt has been determined during a complete, closed cycle of reduction and subsequent oxidation of the melt. There are several advantages to this experimental technique. Firstly, the two largest sources of imprecision between individual viscosity determinations, spindle immersion and sample tem- 
perature, are undisturbed during such a series of viscosity determinations. Secondly, the compositional imprecision arising from the use of separate batches of sample for viscosity determinations at different oxidation states has been avoided in this work by performing a stepwise cycle of viscosity determinations on a single sample. Thirdly, and finally, the direct sampling of the melt for ${ }^{57} \mathrm{Fe}$ Mössbauer spectroscopic determinations of ferric-ferrous ratios and iron coordination during the viscometry experiments provides a chemical monitor of the melts during physical property determinations. The comparison of the viscosity and structure data form the basis for the discussion of the results of this study.

\section{Previous investigations}

There have been several studies of the viscosity of ironbearing silicate melts (e.g. KOZAKEVITCH, 1949; JOHANNSEN and BRUNION, 1959; RONTGEN et al., 1960; MYSEN et al., $1985 \mathrm{~b}$ ) but there are relatively few investigations of the relationship between oxidation state and viscosity in iron-bearing silicate melt systems.

In an investigation of the effects of iron oxides on crystallization kinetics of $\mathrm{CaO}-\mathrm{MgO}-\mathrm{Al}_{2} \mathrm{O}_{3}-\mathrm{SiO}_{2}$ glasses, WLLLAMSON $e$ al (1968), determined viscosity-temperature relationships for an iron-bearing glass at two different oxidation states. Measurements were made using the fiber elongation method (LILLIE, 1931) in the temperature range of $750-900^{\circ} \mathrm{C}$. Reduction of the glass composition from $\left(\mathrm{Fe}^{3+} / \Sigma \mathrm{Fe}=\right) 0.87$ to 0.30 resulted in a viscosity decrease of $0.3 \log _{10}$ units that was independent of temperature.

CUKIERMAN and UHLMANN (1974) described the effect of oxidation on the viscosity-temperature relationship of a synthetic glass equivalent to an iron-rich $(22.5 \mathrm{wt}$. $\% \mathrm{FeO}$ ) lunar mare basalt (15555). Viscosity measurements were made using the beam-bending method (CUKIERMAN et al., 1972) in the temperature range of $600-800^{\circ} \mathrm{C}$. Two relatively reduced compositions ( $\mathrm{Fe}^{3+} / \mathrm{\Sigma Fe}=0.06$ and 0.24 ) yielded the same viscosity-temperature relationship, whereas a third, relatively

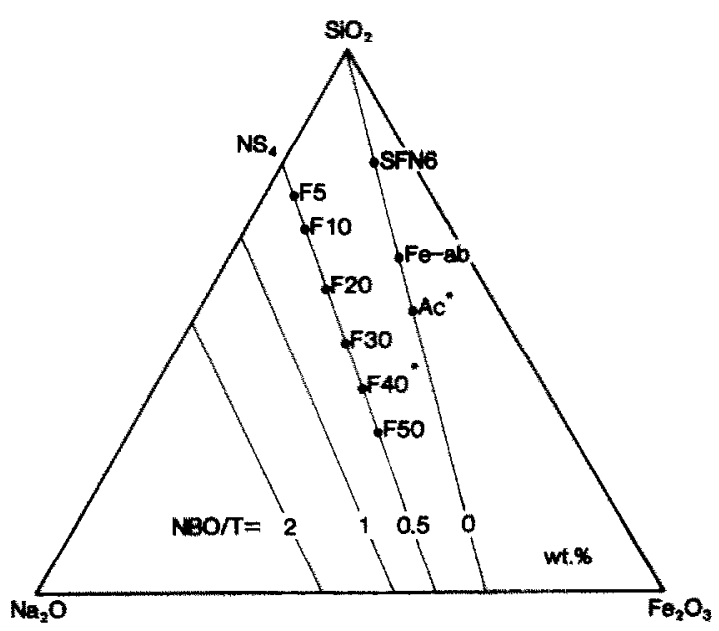

FIG. 1. The compositions of melts investigated in this study (NS4F40 and acmite marked by asterisks) in the fully oxidized system $\mathrm{Na}_{2} \mathrm{O}-\mathrm{Fe}_{2} \mathrm{O}_{3}-\mathrm{SiO}_{2}$. The compositional joins containing NS4F40 and acmite melts yield calculated values of NBO/T equal to 0.5 and 0 , respectively. NS4F40 and acmite melts contain similar weight percents of $\mathrm{Fe}$, differing only in $\mathrm{Na} /$ Si. Fig. 1 is in weight percent. oxidized composition $\left(\mathrm{Fe}^{3+} / \mathrm{Ve}=0.80\right)$ was $3 \log _{10}$ units more viscous.

TOGURI et al. (1976) investigated melt viscosities in the system $\mathrm{FeO}-\mathrm{Fe}_{2} \mathrm{O}_{3}-\mathrm{SiO}_{2}$ at $\mathrm{Fe} / \mathrm{Si}(\mathrm{wt} . \%)=3.09,3.88$, and 499. Measurements were performed using the concentric cylinder method in the temperature range of $1200-1350^{\circ} \mathrm{C}$. ToGURl et al (1976) observed decreases in viscosity of 5 and $40 \%$ during reduction of melts with $\mathrm{Fe} / \mathrm{Si}(\mathrm{wt} . \%)=3.09$ and 3.88 , respectively, as $\mathrm{DO}_{2}$ was varied from $10^{-7}$ to $10^{-11}$ atm.

KLEIN et al. (1983) determined the viscosity-temperature relationship of $\mathrm{Na}_{2} \mathrm{O}-\mathrm{Al}_{2} \mathrm{O}_{3}-\mathrm{SiO}_{2}-\mathrm{Fe}-\mathrm{O}$ glasses produced from a melt that was equilibrated with air $\left(\mathrm{Fe}^{3+} / \Sigma \mathrm{Fe}=0.83\right)$, forming gas $\left(95 \% \mathrm{~N}_{2}, 5 \% \mathrm{H}_{2}\right)\left(\mathrm{Fe}^{3+} / \mathrm{ZFe}=0.72\right)$ and forming gas with carbon $\left(\mathrm{Fe}^{3+} / \Sigma \mathrm{Fe}=0.40\right)$. The measurements were performed using the beam bending technique in the temperature range of $500-650^{\circ} \mathrm{C}$. Both of the relatively reduced glasses yielded the same viscosity-temperature relationship, whereas the most oxidized glass has a viscosity that was higher than the reduced glasses by 0.25 to $0.50 \log _{10}$ units with the largest viscosity increase at lower temperature.

More recently, SEKI and OETERS (1984) have investigated melt viscosities in the system $\mathrm{CaO}-\mathrm{FeO}-\mathrm{Fe}_{2} \mathrm{O}_{3}-\mathrm{SiO}_{2}$. The con centric cylinder method was used in the temperature range of $1200-1500^{\circ} \mathrm{C}$. Rulk compositions whose reduced compositions project near hedenbergite in the system $\mathrm{CaO}-\mathrm{FeO}$ $\mathrm{SiO}_{2}$ yielded higher viscosities (by $20-30 \%$ ) when equilibrated with $\mathrm{CO}_{2}$ than when equilibrated with air.

\section{EXPERIMENTAL}

\section{Starting materials}

The melt compositions investigated by DINGWELL and Vtroo (1986 and present study) are plotted in the system $\mathrm{Na}_{2} \mathrm{O}-\mathrm{Fe}_{2} \mathrm{O}_{3}-\mathrm{SiO}_{2}$ in $\mathrm{Fig}$. 1. Two of these melt compositions were chosen for the present investigation of the effect of the ferric-ferrous ratio on melt viscosity. The compositions chosen (denoted F40 and acmite in Fig. 1) have similar total iron contents but different values of bulk polymerization. ${ }^{57} \mathrm{Fe}$ Mössbauer spectra of quenched glasses of NS4F40 $\left(0.6 \mathrm{Na}_{2} \mathrm{Si}_{4} \mathrm{O}_{9}+0.4 \mathrm{Na}_{6} \mathrm{Fe}_{4}^{3+} \mathrm{O}_{9}\right)$ and acmite composition indicate that melts of these compositions, equilibrated in air at temperatures above $1000^{\circ} \mathrm{C}$, contain $>95 \%$ of iron present as tetrahedrally coordinated ferric ions (DINGWELl and VIRGO, 1986).

The degree of polymerization of silicate melts may be expressed in terms of the ratio of non-bridging oxygens to tetrahedrally coordinated cations (NBO/T). If the melt is assumed to contain only bridging and non-bridging oxygens (i.e., no "free oxygens" in the sense of TOOP and SAMIS, 1962) then the value of $\mathrm{NBO} / \mathrm{T}$ may be calculated as $(2 \mathrm{O}-4 \mathrm{~T}) / \mathrm{T}$, where $O$ is the total number of oxygens per unit of melt and $T$ is the number of tetrahedral cations per unit of melt. Arguments against the presence of a significant proportion of free oxygens in silicate melts more polymerized than orthosilicates (NBO/ $T=4)$ have been put forth by MYSEN et al. (1982; Fig. 10). Recently, GolDMAN (1986) has measured the concentration of non-bridging oxygens for melts in the system $\mathrm{Na}_{2} \mathrm{O}$ - FeO$\mathrm{Fe}_{2} \mathrm{O}_{3}-\mathrm{SiO}_{2}$ using electron spectroscopy (ESCA) and has concluded that the concentrations of non-bridging and bridging. oxygens observed match the proportions that were calculated by the above method. The bulk polymerization of the melts investigated in this study, expressed as the ratio of non-bridging oxygens to tetrahedrally coordinated cations (NBO/T), is equal to 0.5 and 0 for NS4F40 and acmite melts, respectively. Therefore the selection of NS4F40 and acmite melts provides a comparison of the effect of ferric-ferrous ratio on the viscosity of relatively depolymerized and fully polymerized silicate melts.

The starting glasses used in this study were synthesized from reagent-grade $\mathrm{Na}_{2} \mathrm{CO}_{3}, \mathrm{Fe}_{2} \mathrm{O}_{3}$, and purified quartz sand. Batches of carbonate and oxides equivalent to a decarbonated weight of $70 \mathrm{~g}$ were ground under alcohol in an agate mortar 
for two hours and melted in a $25 \mathrm{cc}$ thin-walled platinum crucible for 2 hours. These batches were poured from the platinum crucible onto a steel plate. Chips of the quenched glass were then melted in a thick-walled viscometry crucible at $1450^{\circ} \mathrm{C}$ and stirred with the viscometry spindle at $100 \mathrm{rpm}$ for $30 \mathrm{~min}$. The viscometry crucible and spindle are described below.

\section{Viscometry}

The viscosity determinations were performed in a vertical tube furnace heated by $\mathrm{MoSi}_{2}$ elements and equipped with a gas-tight alumina muffle tube and a $\mathrm{CO}-\mathrm{CO}_{2}$ gas-mixing line. The ambient oxygen fugacity in the furnace was fixed by controlling the furnace atmosphere at air, pure $\mathrm{CO}_{2}$ and several $\mathrm{CO}-\mathrm{CO}_{2}$ mixing ratios. The crucible was supported in the "hot zone" of the furnace by an alumina pedestal. The "hot zone" of the furnace shifted with the introduction of the sample and the pedestal and thus the "hot zone" had to be determined by a trial and error method involving successive adjustments of the height of the pedestal. The temperature profile of the final configuration was determined by the immersion of a Pt$\mathrm{Pt}_{90} \mathrm{Rh}_{10}$ thermocouple (shielded by a platinum sheath) into the melt sample. Stable, vertical and radial temperature gradients of $1.5^{\circ} \mathrm{C} / \mathrm{cm}$ were recorded.

Viscosities were measured at 1 atm and temperatures of $1430^{\circ} \mathrm{C}$ and $1200^{\circ} \mathrm{C}$ for the acmite and NS4F40 melts, respectively, with the concentric cylinder method. The samples were contained in cylindrical $\mathrm{Pt}_{80} \mathrm{Rh}_{20}$ crucibles $(5.1 \mathrm{~cm}$ height, $2.56 \mathrm{~cm}$ inner diameter, $0.1 \mathrm{~cm}$ wall thickness).

Viscosities were measured with a Brookfield RVTD viscometer head. This viscometer head drives a spindle at a range of constant angular velocities $(0.5$ to $100 \mathrm{rpm})$ and digitally records the torque exerted on the spindle by the sample. The $\mathrm{Pt}_{80} \mathrm{Rh}_{20}$ spindle used in this study has the cross-section of a cylinder $\left(1.44 \mathrm{~cm}\right.$ diameter, $3.32 \mathrm{~cm}$ length) with $45^{\circ}$ conical ends to reduce end effects and a $0.24 \mathrm{~cm}$ diameter stem.

The spindle and head were calibrated for viscosity measurements with the NBS SRM 711 lead-silica glass for which the viscosity-temperature relationship is accurately known. The precision of viscosity determinations for this apparatus $( \pm 3 \%$ at the $2 \sigma$ level, DINGWELL, 1986a) was derived from replication of viscosity determinations of NBS SRM 711 involving successive immersions of the spindle and reoccupations of the temperature setting.

In this study the viscosity determinations as a function of ferric-ferrous ratio were performed during a single cycle of melt reduction and oxidation during which two significant sources of imprecision, the temperature and the position of the spindle, were not disturbed. Thus, although the precision of these measurements is probably better (see Results), the value of $\pm 3 \%$ may be taken as a maximum imprecision. The accuracy of determinations is taken as the sum of the uncertainties from standard and sample determinations, equal to $\pm 6 \%$ at the $2 \sigma$ level.

The redox cycle viscometry experiments were performed in the following manner. The sample-bearing crucible was loaded through the top of the vertical tube furnace onto the ceramic pedestal. The viscometry spindle was connected to the viscometer head that was located approximately $25 \mathrm{~cm}$ above the furnace tube and lowered by a rack and pinion mechanism into the sample. During the experiments, the upper tube fitting was capped by a split circle, brass cap with a 0.5 $\mathrm{cm}$ axial hole, which allowed passage of the spindle into the furnace with a minimum of exposure of the inner gas atmosphere to air. In practice, the gas-flow atmospheres were sufficiently reducing to yield melt $\mathrm{Fe}^{3+} / \Sigma \mathrm{Fe}$ values as low as 0.2 . The viscometry determinations were initiated by equilibrating the melt sample with air. The rotation speed used in the determinations was 50 or $100 \mathrm{rpm}$ and the equilibration of the melt viscosity was monitored with a chart recorder that recorded the torque measured by the viscometer head as a function of time. At the beginning of the experiments, in air, the viscometer achieved stable, time-invariant readings within 0.5 to 1.0 hours. The melt was reduced by flowing pure $\mathrm{CO}_{2}$ gas, and then $\mathrm{CO}-\mathrm{CO}_{2}$ gas mixtures, through the tube furnace. For each melt reduction and viscosity determination, the melt was permitted to equilibrate to a time-invariance of the viscometer reading as monitored by the chart recorder. Twentyfour to 30 hours were required for the equilibration of $60 \mathrm{~g}$ of melt (with continuous stirring) during successive stages of reduction. After the final viscosity determination under controlled atmosphere was obtained, the $\mathrm{CO}-\mathrm{CO}_{2}$ gas flow was shut off and the melt was permitted to re-equilibrate with air. This re-equilibration involved a relatively large step in $f \mathrm{O}_{2}$ compared with the successive reduction intervals and required 8 and 10 days, respectively, for the NS4F40 and acmite compositions. Oxidation and reduction of iron-rich melts involves the transport of significantly large quantities of oxygen gas. In dynamic experiments such as these viscosity runs, oxygen transport must occur, in part, by some combination of chemical diffusion in response to oxygen activity gradients in the melt and melt convection due to the shear stress applied to the melt by the rotating spindle. The observed, rapid equilibration of $60 \mathrm{~g}$ samples was undoubtedly facilitated by 1 ) the low viscosities of the melts investigated (1.4-23 poise) which probably correspond to very high oxygen diffusivities $\left(=10^{-5}\right.$ $\mathrm{cm}^{2} / \mathrm{sec}$. SHIMIZU and KUSHIRO, 1984) and 2) the high (50$100 \mathrm{rpm}$ ) rotation rates that produced a forced convective flow regime in the melt enhancing the rate of convective oxygen transport from the melt. In addition, the longer time period required for oxidation of the melts has led the present authors to speculate that the reduction rate may be enhanced due to the nucleation and escape of oxygen gas bubbles. Indeed, GOLDMAN et al. (1986) have investigated the phenomena of foaming during reduction of melts in the system $\mathrm{Na}_{2} \mathrm{O}-\mathrm{FeO}$ $\mathrm{Fe}_{2} \mathrm{O}_{3}-\mathrm{SiO}_{2}$ and conclude that oxygen loss is the principal causc for foaming.

\section{Loop fusion and viscometry samples}

The melt was sampled at each redox step during the viscometry experiments. These samples were obtained by dipping a platinum wire into the melt and withdrawing approximately $100 \mathrm{mg}$ of melt which was quenched in water. ${ }^{57} \mathrm{Fe}$ Mössbauer spectra of samples obtained using this sampling technique are in agreement with those obtained on smaller loop samples (approx. $30 \mathrm{mg}$ ) that were drop quenched into both water and liquid $\mathrm{N}_{2}$ (DINGWELL and VIRGO, 1986).

The bulk composition of samples of melts equilibrated in air, obtained at the start and end of each cycle of viscosity measurements was determined by electron microprobe analyses of quenched melts. It is clear from the data of Table 1 that the compositions of the samples of NS4F40 and acmite melts did not change during the viscometry experiments.

Table 1, Analyzed melt compositions.

\begin{tabular}{lccccccc}
\hline \hline & \multicolumn{3}{c}{ Acm1te } & \multicolumn{3}{c}{ NS4F40 } \\
\hline & $\begin{array}{l}\text { Pre } \\
\text {-run }\end{array}$ & $\begin{array}{l}\text { Post } \\
\text {-run }\end{array}$ & $\begin{array}{l}\text { Stolchio } \\
\text {-metr1c }\end{array}$ & $\begin{array}{l}\text { Pre } \\
\text {-run }\end{array}$ & $\begin{array}{l}\text { Post } \\
\text {-run }\end{array}$ & $\begin{array}{l}\text { Sto1ch10 } \\
\text {-metr1c }\end{array}$ \\
\hline $\mathrm{Na}_{2} \mathrm{O}$ & 14.10 & 14.15 & 13.41 & 29.05 & 28.42 & 29.09 \\
$\mathrm{Fe}_{2} \mathrm{O}_{3} *$ & 35.78 & 34.91 & 34.56 & 34.27 & 34.86 & 33.31 \\
$\mathrm{SiO}_{2}$ & 50.12 & 50.95 & 52.02 & 36.68 & 36.72 & 37.60 \\
total $(100.51)$ & $(99.41)$ & & $(101.51)$ & $(100.80)$ &
\end{tabular}

*total Iron as $\mathrm{Fe}_{2} \mathrm{O}_{3}$

-analyses are normalized to $100 \pi$ to facilitate compar1sons,

numbers in brackets ate microprobe totals, glasses were

analyzed by wavelength dispersive methods using a JEOL

JSM-35 Instrument and Krisel control system. Operating con-

ditions included a $15 \mathrm{kV}$ accelerating voltage, a $60 \mathrm{nA}$

beam current on carbon, $30 \mathrm{sec}$, max. count times and a

$10 \times 10$ micron rastor, in addition to moving the sample stage continuous1y under the beam. Standards were ayn-

thet1c glasses, the max. rel, uncertainties at 3 atd. dey.

are $\pm 2.47(\mathrm{Na}), \pm 2.0 z$ (Fe) $\pm 1.7 \%$ (S1). Oxygen by stotchio

metry. 
${ }^{57} \mathrm{Fe}$ Mössbauer spectra obtained on samples from the viscometry experiments permit the calibration of the viscosity of these melts as a function of $\mathrm{Fe}^{3+} / \Sigma \mathrm{Fe}$. In order to translate these data into a viscosity- $f \mathrm{O}_{2}$ relationship, a series of loop fusion experiments was performed on these two melt compositions. These experiments were performed by suspending approximately $30 \mathrm{mg}$ of powdered glass on a fine platinum wire loop in the controlled atmosphere of the vertical tube furnace, fitted with a gas-tight cap. The $f \mathrm{O}_{2}$ was controlled by $\mathrm{CO}-\mathrm{CO}_{2}$ gas mixtures and monitored by a yittria-stabilized, zirconia-based, oxygen electrode, calibrated against air and pure $\mathrm{CO}_{2}$. The loop fusion experiments were run for 1 hour at the temperature of interest $\left(1430\right.$ or $\left.1200^{\circ} \mathrm{C}\right)$ and then quenched into water. These experiments permit the calibration of $\mathrm{Fe}^{3+} / \mathrm{\Sigma Fe}$ as a function of $f \mathrm{O}_{2}$ and therefore fix the dependence of viscosity on $f \mathrm{O}_{2}$.

\section{${ }^{37} \mathrm{Fe}$ Mössbauer spectra}

The ${ }^{57} \mathrm{Fe}$ Mössbauer spectra of the quenched glasses were measured to determine the oxidation state and the structural states of both ferric and ferrous iron in both the loop and viscometry samples. The resonant absorption spectra were recorded at $298 \mathrm{~K}$ with a $25 \mathrm{mC} \mathrm{Co} / \mathrm{Pd}$ source on powdered samples mixed with plastic transoptic powder and pressed into thin discs. The absorber thickness was constrained to $\approx 5$ $\mathrm{mg} \mathrm{Fe} / \mathrm{cm}^{2}$. Mirror image spectra were recorded over 512 channels. The data were analyzed separately and the results are the average values obtained from the left and right sides. The spectral data were deconvoluted with a least-squares routine using Lorentzian lines and with area and width constraints as discussed by VIRGO and MYSEN (1985).

A general description of the ${ }^{57} \mathrm{Fe}$ Mössbauer spectra of disordered solids containing either trivalent or divalent iron, or both, has been given by VIRGO and MYSEN (1985) and DYAR (1985). In this study the spectral data were deconvoluted with a least-squares routine using lines of Lorentzian shape and with area and width constraints for the component peaks of the ferric absorption doublet and area constraints of the component peaks of the ferrous doublet. An interlaboratory comparison of ferrous/ferric values of silicate glasses obtained using ${ }^{37} \mathrm{Fe}$ Mössbauer spectroscopy and wet chemical techniques has been reported by MYSEN et al. (1985c). In their study, the resonant absorption spectra were fitted with lines of Lorentzian shape and with the same area and width constraints used in this study (VIRGO and MYSEN, 1985). MYSEN et al. (1985c) demonstrated that $70 \%$ of the ferrous/ferric analyses by ${ }^{57} \mathrm{Fe}$ Mössbauer and by wet chemical techniques were within $\pm 1 \sigma$ and $83 \%$ were within $\pm 2 \sigma$ of each other. There was no systematic bias between the results of both techniques as a function of $\mathrm{Fe}^{3+} / 2 \mathrm{Fe}$.

Recently, GoLDMAN and BEWLEY (1985) have proposed that area ratios from ${ }^{57} \mathrm{Fe}$ Mössbauer spectra of chemically complex glasses developed for nuclear waste storage overestimate the proportion of ferrous iron by a factor of 1.5 . In this latter study, the line shape used to fit the spectral data is a linear combination of Lorentzian and Gaussian profiles and the ferrous/ferric values were determined by statistically optimizing the proportion of the Gaussian component in the composite line profiles. It is well known, however, that the line profile of the cumulative envelope of paramagnetic Mössbauer spectra of glasses is largely the result of a distribution of the hyperfine fields (WIVEL and MORUP, 1981; DANCKWERTH, 1982). Fitting models that solve for such distributions will, of course, result in a more accurate description of the mathematical description of the cumulative envelope (e.g. ErBschuTz et al., 1980). On the other hand, the use of the alternative line profiles (VIRGO and MYSEN, 1985; GOLDMAN and BEWLEY, 1985) is, to a large extent, a mathematical expediency. In the latter case, VIRGO and MYSEN (1985) have cautioned against the use of statistical parameters, a priori, because the values of such parameters will, in part, reflect the numerical description of the profile of the cumulative envelope in addition to a test of different structural models of the spectral data.

\section{RESULTS}

\section{Viscometry and loop fusions}

The results of the reduction-oxidation cycles of viscosity determinations on acmite and NS4F40 melts are presented in Table 2 . The $\mathrm{Fe}^{3+} / \Sigma \mathrm{Fe}$ values in Table 2 are those determined from ${ }^{57} \mathrm{Fe}$ Mössbauer spectra of samples obtained during the viscometry experiments (Table 3). The viscosity data for acmite melt at $1430^{\circ} \mathrm{C}$ are presented in Fig. 2 where it is apparent that the reduction of acmite melt from $\mathrm{Fe}^{3+} / 2 \mathrm{Fe}$ values near 1.0 results in a decrease in melt viscosity. The decrease in melt viscosity is approximately $0.38 \log _{10}$ units or a factor of 2.4 from a viscosity of 23 poise for the most oxidized melt to a viscosity of 9.5 poise for the most reduced melt. The sequence of viscosity determinations is from oxidized to reduced except for the final viscosity determination which was obtained at the end of the reduction-oxidation experimental cycle (square, Fig. 2). The viscosity determinations for the acmite melt in equilibrium with air at the start and finish of the reduction-oxidation cycle are equal, within the errors of the viscosity and oxidation state determinations. It should be noted that the reduction of viscosity is not a linear function of $\mathrm{Fe}^{3+} / \mathrm{\Sigma Fe}$. The curvature of $\log$ viscosity versus $\mathrm{Fe}^{3+} / \Sigma \mathrm{Fe}$ yields a composition-invariance of melt viscosity at $\mathrm{Fe}^{3+} / \Sigma \mathrm{Fe}$ values below 0.4 . Despite the non-linearity of the $\log$ viscosity versus $\mathrm{Fe}^{3+} / \Sigma \mathrm{Fe}$ relationship, however, the viscosity decrease does describe a continuous function within the errors of measurements.

For comparison, the viscosity of NS4F40 is plotted as a function of $\mathrm{Fe}^{3+} / \Sigma \mathrm{Fe}$ in Fig. 3. The same general behavior is observed for this melt composition. The decrease in viscosity is $0.8 \log _{10}$ units or a factor of 6.5 from the most oxidized to the most reduced samples. The trend of decreasing log viscosity with melt reduction is curved such that the viscosities of the more reduced melts are either independent or only very slightly dependent on oxidation state. The data may be fitted to a smooth curve within the limits of measurement errors and the final oxidized melt viscosity

Table 2, Viscometry results.

\begin{tabular}{|c|c|c|c|c|c|}
\hline & \multicolumn{2}{|c|}{ Acmite $\left(1430^{\circ} \mathrm{C}\right)$} & \multicolumn{3}{|c|}{$\operatorname{NS} 4 F 40\left(1200^{\circ} \mathrm{C}\right)$} \\
\hline & $\log _{10} \eta$ & $\mathrm{Fe}^{3+} /$ tot $\cdot \mathrm{Fe}^{\star \star}$ & & $\log _{10} \eta$ & $\mathrm{Fe}^{3+} /$ tot. Fe \\
\hline$A C-1$ & 1.36 & $(a f r)$ & $\mathrm{P} 40-1$ & 0.925 & (a1r) \\
\hline $\mathrm{AC}-$ & 1.19 & 0.82 & 740 & 0.886 & 0.98 \\
\hline$A C-3$ & 1.01 & 0.52 & $740-3$ & 0.183 & 0.47 \\
\hline$A C-4$ & 0.976 & 0.37 & $540-4$ & 0.135 & 0.28 \\
\hline$A C-5$ & 0.977 & 0.25 & $(740-5)$ & $(0.232)$ & $(0.35)$ \\
\hline$A C-6$ & 0.977 & 0.18 & $540-6$ & 0.348 & 0.63 \\
\hline $\mathrm{AC}-7$ & 1.32 & $0.92(\mathrm{atx})$ & $540-8$ & 0.948 & $1.00(a 1$ \\
\hline
\end{tabular}

(In poloe; \pm .025 at 2 atd. dev.

$* *(2,02$ at 2 std. dev. $)$

F40-5 is diacusaed in text; (air) 1ndicates that the gample was equilibrated in a1r, the data are 1isted in the sequence in which they were obtatned. 
Table 3. ${ }^{57}$ Fe Mossbauer parameters at $298 \mathrm{R}$ for NS4F40 glass aynthesized at $1473 \mathrm{~K}\left(1200^{\circ} \mathrm{C}\right)$ and at different values of oxygen fugacity.

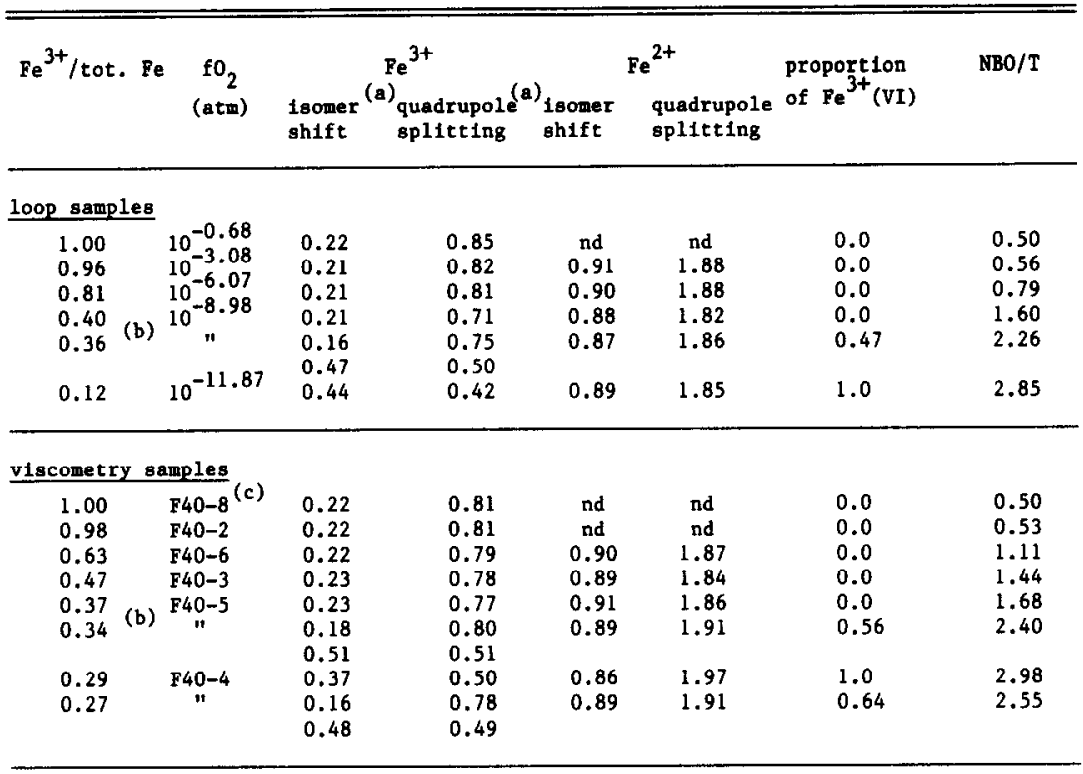

${ }^{57} \mathrm{Fe}$ Mossbauer parameters at $298 \mathrm{~K}$ for acmite glass synthesized

at $1703 \mathrm{~K}\left(1430^{\circ} \mathrm{C}\right)$ and at different values of oxygen fugactity.

\begin{tabular}{|c|c|c|c|c|c|}
\hline \multicolumn{6}{|c|}{ loop samples } \\
\hline $\begin{array}{l}0.91 \\
0.56 \\
0.21\end{array}$ & $\begin{array}{l}10^{-0.68} \\
10^{-2.80} \\
10^{-5.68}\end{array}$ & $\begin{array}{l}0.23 \\
0.24 \\
0.41\end{array}$ & $\begin{array}{l}0.91 \\
0.81 \\
0.47\end{array}$ & $\begin{array}{l}0.90 \\
0.90 \\
0.93\end{array}$ & $\begin{array}{l}1.89 \\
1.75 \\
1.93\end{array}$ \\
\hline \multicolumn{6}{|c|}{ viscometry samples } \\
\hline $\begin{array}{l}0.92 \\
0.82 \\
0.52 \\
0.37 \\
0.25 \\
0.18\end{array}$ & $\begin{array}{l}\mathrm{AC}-7 \text { (c) } \\
\mathrm{AC}-2 \\
\mathrm{AC}-3 \\
\mathrm{AC}-4 \\
\mathrm{AC}-5 \\
\mathrm{AC}-6\end{array}$ & $\begin{array}{l}0.23 \\
0.24 \\
0.25 \\
0.40 \\
0.41 \\
0.46\end{array}$ & $\begin{array}{l}0.86 \\
0.87 \\
0.84 \\
0.56 \\
0.47 \\
0.39\end{array}$ & $\begin{array}{l}0.88 \\
0.91 \\
0.94 \\
0.88 \\
0.89 \\
0.91\end{array}$ & $\begin{array}{l}1.82 \\
1.75 \\
1.81 \\
1.98 \\
1.86 \\
1.85\end{array}$ \\
\hline
\end{tabular}

(b) see text for discussion

(c) see F1gures 4 and 5 for $\mathrm{fO}_{2}$

determination is within error of the initial oxidized melt viscosity determination. The hexagon in Fig. 3 is a problematic data point that corresponds to a sample which was set at a more reducing $\mathrm{CO}-\mathrm{CO}_{2}$ ratio than any of the other data points in Fig. 3. This sample was

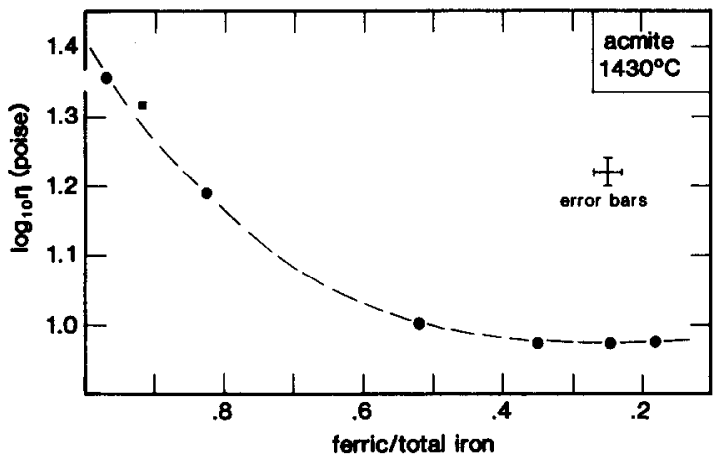

FIG. 2. The viscosity of acmite melt as a function of $\mathrm{Fe}^{3+} /$ $\mathrm{\Sigma Fe}$. The viscosity determinations were made in the order of decreasing $\mathrm{Fe}^{3+} / \Sigma \mathrm{Fe}$ except for the final oxidized determination (square). probably contaminated with oxidized melt residue deposited in a cooler part of the furnace (due to accidental contact of the viscometry spindle with the furnace tube)

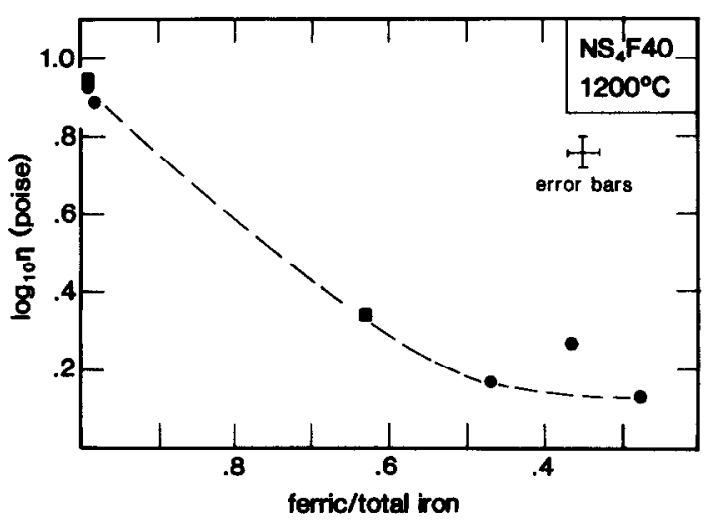

FIG. 3. The viscosity of NS4F40 melt as a function of $\mathrm{Fe}^{3+}$ / $\Sigma F e$. The circles are viscosity determinations during melt reduction steps and the squares are viscosity determinations made during melt oxidation steps. The hexagon is a problematic data point discussed in the text. 
during the removal of the sample from the furnace. The relatively high $\mathrm{Fe}^{3+} / 2 \mathrm{Fe}$ content of the sample obtained at this stage in the experiment cannot have represented an equilibrium sample of the melt under the designated conditions of the experiment and it has been discarded in the discussion of these data.

Although direct comparison of the changes in bulk viscosity of acmite and NS4F40 melts as a function of oxidation state is of limited use in view of the fact that the measurements were performed at different temperatures and the viscosity-temperature relationships of melts of varying oxidation state in this system are not yet known; it is observed that the viscosity change is considerably larger for the NS4F $40\left(1200^{\circ} \mathrm{C}\right)$ experiment than for the higher temperature acmite $\left(1430^{\circ} \mathrm{C}\right)$ experiment. The data of Figs. 2 and 3 indicate that the relationship between viscosity and oxidation state is independent of the initial degree of polymerization of the melt, inasmuch as acmite and NS4F40 melts exhibit the same qualitative behavior.

The data from the loop fusion experiments that are used to calibrate the ferric-ferrous ratios of the acmite and NS4F40 melts in terms of oxygen fugacity are given in Table 3 and plotted in Figs. 4 and 5. The linear fit of $\log$ ferrous/ferric values to $\log \mathrm{fO}_{2}$ is well within the errors of determinations $\left(\mathrm{Fe}^{3+} / \Sigma \mathrm{Fe}, \pm 2 \% ; \log f \mathrm{O}_{2}\right.$, \pm 0.05 ) and the equations of the lines describing the ferrous/ferric- $f \mathrm{O}_{2}$ relationships yield slope values of -3.85 and -3.12 for the NS4F40 and acmite melts, respectively. Several workers have discussed the significance of the value of the slope of the linear relationship between $\log$ (ferrous/ferric) and $\log f \mathrm{O}_{2}$ in terms of the heterogeneous equilibria involving gas and melt (e.g., PAUL and Douglas, 1965; Goldman, 1983; MYSEN, 1986). The ferrous/ferric-f $\mathrm{O}_{2}$ relationships observed in this study are similar to those found

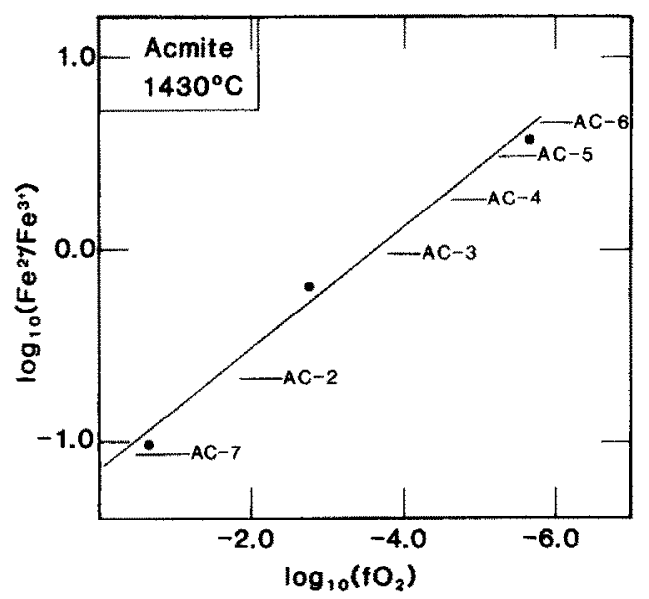

FIG. 4. The ferrous/ferric value of acmite melt as a function of oxygen fugacity at $1430^{\circ} \mathrm{C}$. The data are from loop fusion experiments. The least-squares regression of the data yields $x$ $=-3.12 y-3.61\left(y=\log _{10}\right.$ ferrous/ferric; $\left.x=\log _{10} \int \mathrm{O}_{2}\right)$. $\mathrm{AC}-2$ to $\mathrm{AC}-7$ indicate the effective $f \mathrm{O}_{2}$ of the viscometry experiments as recorded by the $\mathrm{Fe}^{3+} / \mathrm{\Sigma Fe}$ contents of quenched melt samples.

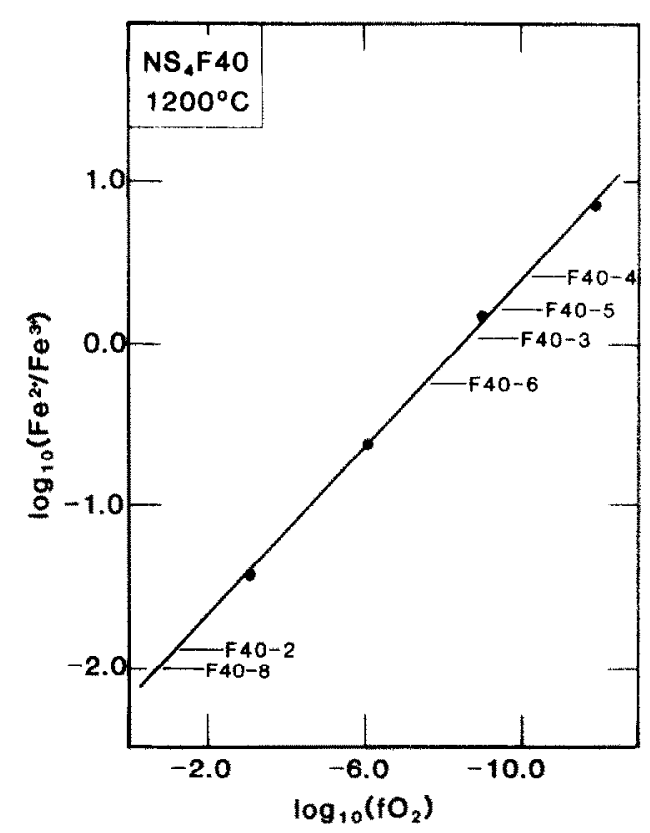

Fic. 5. The ferrous/ferric value of NS4F40 melt as a function of oxygen fugacity (symbols as in Fig. 4). The least squares regression yields $x=-3.85 y-8.48$.

by previous workers in that the relationship is linear and that the magnitude and temperature-dependence of the slopes are similar to that observed in previous studies (e.g. GoldMAN, 1983).

\section{${ }^{57} \mathrm{Fe}$ Mössbauer spectra at $298 \mathrm{~K}$}

The ${ }^{57} \mathrm{Fe}$ Mössbauer parameters, quadrupole splittings and isomer shifts, at $298 \mathrm{~K}$, for both ferrous and ferric iron are reported in Table 3. The values of the isomer shifts for both ferrous and ferric iron are plotted versus $\mathrm{Fe}^{3+} / 2 \mathrm{Fe}$ in Fig. 6.

The spectra of the oxidized glasses exhibit three resolved peaks ( $c f$. VIRGO and MYSEN, 1985, Fig. 3), two of which are in the positive velocity region and therefore, at least two quadrupole split doublets are required in fitting the spectral data (Table 3). The doublets with the larger and smaller quadrupole splittings are assigned to ferrous and ferric iron, respectively (Table 3 ). The spectra of the samples with $\mathrm{Fe}^{3+} / 2 \mathrm{Fe}<0.4$ are different than those of the oxidized glasses in that the positive velocity ferric iron peak is not resolved ( $c f$. VIRGO and MYSEN, 1985, Fig. 3). In these latter samples the presence of ferric iron can be inferred because the areas of the component peaks of the ferrous iron doublet are unequal (MAO et al., 1973). In addition, the ferricferrous ratio is qualitatively constrained by the theoretical relationship between $\log$ ferrous/ferric and $\log$ $f \mathrm{O}_{2}$ (e.g., GOLDMAN, 1983).

On the basis of the fits to the spectral data assuming single ferrous and ferric quadrupole split doublets, the values of the isomer shift for ferric iron in both NS4F40 and acmite glasses are invariant with respect to oxidation state for $\mathrm{Fe}^{3+} / \Sigma \mathrm{Fe}>\sim 0.4$ (Table 3, Fig. 6). 


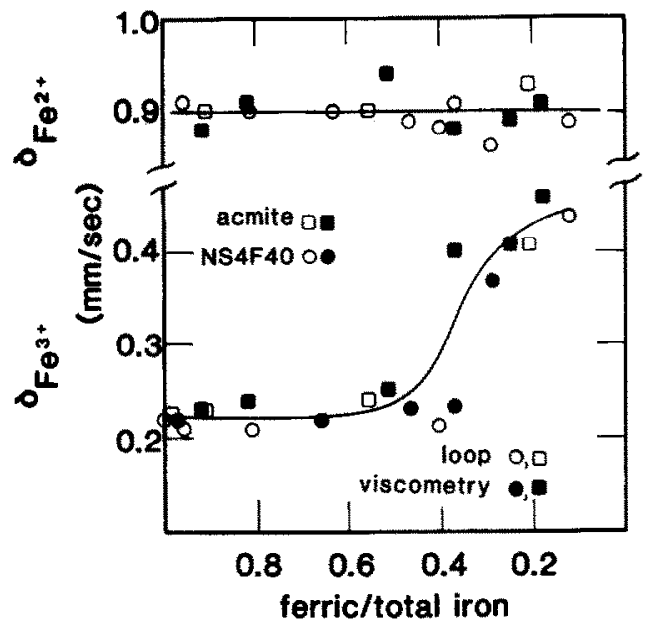

FIG. 6. The isomer shift values of ferrous and ferric iron doublets as a function of $\mathrm{Fe}^{3+} / \mathrm{\Sigma Fe}$. Note the invariance of the ferrous isomer shift over the entire range of $\mathrm{Fe}^{3+} / \Sigma \mathrm{Fe}$ in contrast to the limited range of ferric isomer shift invariance. The change in ferric isomer shift is interpreted in the text to indicate the presence of a second coordination state for ferric iron in these glasses. The open symbols are loop fusion experimental data, the closed symbols are viscometry experimental data. Note that the viscometry and loop samples yield equivalent isomer shift data and that acmite (squares) and NS4F40 (circles) data exhibit similar trends.

The isomer shift for ferrous iron is, to a first approximation, invariant over the range of $\mathrm{Fe}^{3+} / \Sigma \mathrm{Fe}$ from 1.0 to 0.12 (Table 3, Fig. 6).

The observed trend in the isomer shift for ferric iron as a function of $\mathrm{Fe}^{3+} / \mathrm{\Sigma Fe}$ for NS4F40 and acmite glasses is similar to that observed for alkali- and alkalialumino-silicate glasses (VIRGO and MYSEN, 1985, Fig. 4). It can be shown from the values of the quadrupole splittings and the isomer shifts (Table 3 ) that there is a systematic increase in the positions of both absorption peaks of the single quadrupole-split doublet assigned to ferric iron, with decreasing $\mathrm{Fe}^{3+} / \Sigma \mathrm{Fe}$. It is herein suggested (and in MYSEN et al, 1984; VIRGO and MYSEN, 1985) that the absorption due to ferric iron consists of two components with values of the isomer shifts and quadrupole splittings that are characteristic of those found for ferric iron in the oxidized and highly reduced glasses (viz NS4F40 glasses synthesized at $\log _{10} f \mathrm{O}_{2}$ $=-11.87 \mathrm{~atm}$, sample F40-4 and sample AC-6). It is thus proposed that the cumulative absorption due to ferric iron in these glasses consists of two distinct structural states as evidenced by the contrasting values of isomer shift. At intermediate values of $\mathrm{Fe}^{3+} / \Sigma \mathrm{Fe}$, the two structural species of ferric iron coexist.

The spectral data of the NS4F40 glasses with $\mathrm{Fe}^{3+}$ / $\Sigma \mathrm{Fe}<0.4$ were fitted, therefore, with an additional ferric doublet (Table 3). It should be noted that such fits are nonunique because, as noted above, the statistical parameters $\left(\chi^{2}\right.$, MISFIT) cannot be used, a priori, to evaluate the "goodness of fit" due to the known distribution of hyperfine fields (VIRGO and MYSEN, 1985). It was not possible to fit two ferric doublets with distinct values of the quadrupole splitting and isomer shift to the spectral data for NS4F40 glass synthesized at $\log _{10} f \mathrm{O}_{2}=-11.87 \mathrm{~atm}$ and for $\mathrm{AC}-6$ glass. Two ferric doublets were fitted to the spectra of F40-5, F40-4 and the NS4F40 glass synthesized at $\log _{10} f_{\mathrm{O}_{2}}$ $=-8.98 \mathrm{~atm}$. The isomer shift values for the ferric component with the smaller value of quadrupole splitting are $0.48,0.51$ and $0.47 \mathrm{~mm} / \mathrm{sec}$ and are in approximate agreement with values found for the glasses with lower values of ferric iron $(\approx 0.45 \mathrm{~mm} / \mathrm{sec})$. In contrast, the values of isomer shift of isomer shift for the ferric component with the larger value of quadrupole splitting (in the range of $0.16-0.18 \mathrm{~mm} / \mathrm{sec}$ ) are systematically lower than the values obtained for the oxidized glasses which were fitted with a single ferric iron component (Table 3). Neither the ferric-ferrous ratios nor the isomer shift of the ferrous iron doublet are affected by the presence of a second ferric iron doublet in the fitting procedure. On the basis of these results, it is suggested that there is an approximately linear increase in the proportion of ferric iron characterized by systematically higher values of isomer shift from 0.0 at $\mathrm{Fe}^{3+} / \Sigma \mathrm{Fe}=0.4$ to 1.0 at $\mathrm{Fe}^{3+} / \Sigma \mathrm{Fe}=0.1$.

\section{Structural assignments of ferrous and ferric iron}

The assignment of the hyperfine parameters of ferrous and ferric iron site occupancies is, in principle, determined from the values for crystals (VIRGO and MYSEN, 1985; DYAR, 1985). For ferrous iron, the cumulative absorption envelope is distinctly asymmetric and the half-widths of the component peaks of the quadrupole splitting doublet are broad. These latter features are a manifestation of a wide range of distortions and electronic densities of the ferrous iron coordination environment in glasses and the calculated values of the hyperfine parameters are, therefore, average values that reflect the continuum of ferrous iron sites. The values of isomer shift for ferrous iron obtained by fitting lines of Lorentzian shape or a linear combination of Lorentzian and Gaussian line profiles are intermediate between the values attributable to ferrous iron in tetrahedral and octahedral coordination (DANCKWERTH, 1982; VIRGO and MYSEN, 1985, Table 3). In their study of alkali- and alkaline earth aluminosilicate glasses, VIRGO and MYSEN (1985) used corroborative evidence from the data of other spectral studies (e.g., infrared, Raman and optical spectra) to demonstrate that ferrous iron in silicate glasses is predominantly in octahedral coordination. It should be noted, however, that the hyperfine field distributions for ferrous iron in glasses are best described by asymmetric Gaussian distributions with a skewness towards lower values of quadrupole splitting and isomer shift (DANCKWERTH, 1982; DANCKWERTH and VIRGO, 1982). These latter results could be taken as evidence for more than one distinct coordination environment for ferrous iron in the long-range structure of glass. In fact, SPIERING and SEIFERT (1985) have shown that in reduced natural and synthetic glasses of granitic com- 
position, the ferrous absorption envelope is split into two components with different isomer shifts and quadrupole splittings. The ranges of measured isomer shifts are $0.91-1.14$ and $1.06-1.22(\mathrm{~mm} / \mathrm{sec})$, respectively, and the existence of two sites is attributable to different anionic units adjacent to ferrous iron (SPIERING and SEIFERT, 1985). The range of values for quadrupole splittings and isomer shifts for both NS4F40 and acmite glasses $(1.75-1.97$ and $0.86-0.94 \mathrm{~mm} / \mathrm{sec}$, respectively) are similar to those found with more polymerized anionic units (SPIERING and SEIFERT, 1985).

Ferric iron occurs in tetrahedral coordination in the oxidized glasses investigated $\left(\mathrm{Fe}^{3+} / \Sigma \mathrm{Fe}>0.4\right)$. The isomer shift values of $0.21-0.25 \mathrm{~mm} / \mathrm{sec}$ lie in the range for tetrahedral ferric iron in crystalline materials (DYAR, 1985). The assignment of ferric iron in NS4F40 and acmite glasses with $\mathrm{Fe}^{3+} / \Sigma \mathrm{Fe}>0.4$ is supported by data from other spectroscopic techniques (see VIRGO and MYSEN, 1985 for review).

The values of the ferric isomer shift $(>0.40)$ for the more reduced glasses $\left(\mathrm{Fe}^{3+} / \Sigma \mathrm{Fe}<0.40\right.$, see Table 3) can be assigned to octahedral ferric iron (VIRGO and MYSEN, 1985; DYAR, 1985). These latter values of the isomer shift are lower than the values (at $298 \mathrm{~K}$ ) reported for alkali-aluminosilicate glasses (VIRGO and MYSEN, 1985), but it should be pointed out that the position of the low velocity component of the quadrupole split doublet may be subject to a degree of uncertainty. This problem of fitting the spectra of glasses is enhanced compared with crystalline spectra because of the distributions of hyperfine fields for both ferrous and ferric iron. The inference that there is a coordination transformation of ferric iron as a function of $\mathrm{Fe}^{3+} / \Sigma \mathrm{Fe}$ at fixed temperature, pressure and bulk composition is consistent with other studies of synthetic glasses (MASSIOT, 1985; SPIERING and SEIFERT, 1985).

\section{DISCUSSION}

\section{Oxidation state and melt polymerization}

If ferric iron were a network-former and ferrous iron were a network-modifier in the melts under consideration in the present study, then the reduction of ferric to ferrous iron would result in depolymerization of the silicate melt. The fully oxidized stoichiometries of acmite and NS4F40 melts have the chemical formulae $\mathrm{NaFe}^{3+} \mathrm{Si}_{2} \mathrm{O}_{6}$ and $\left(0.4 \mathrm{Na}_{6} \mathrm{Fe}_{4}{ }^{3{ }^{3}} \mathrm{O}_{9}+0.6 \mathrm{Na}_{2} \mathrm{Si}_{4} \mathrm{O}_{9}=\right)$ $\mathrm{Na}_{3.6} \mathrm{Fe}_{1.6}^{3+} \mathrm{Si}_{2.4} \mathrm{O}_{9}$, respectively. The calculated values of NBO/T of these melts, based on tetrahedral coordination of ferric iron, are 0.0 and 0.5 , respectively. Inasmuch as melts of acmite and NS4F40 composition are virtually fully oxidized in air, these calculated values of NBO/T may be used to represent the polymerization state of the acmite and NS4F40 melts in equilibrium with air.

Similarly, the fully reduced stoichiometries of the acmite and NS4F40 melts (i.e., all ferrous iron) are $\mathrm{NaFe}^{2+} \mathrm{Si}_{2} \mathrm{O}_{5.5}$ and $\left(0.4 \mathrm{Na}_{6} \mathrm{Fe}_{4}^{2+} \mathrm{O}_{7}+0.6 \mathrm{Na}_{2} \mathrm{Si}_{4} \mathrm{O}_{9}=\right)$ $\mathrm{Na}_{3.6} \mathrm{Fe}_{1.6}^{2+} \mathrm{Si}_{2.4} \mathrm{O}_{8.2}$ and the calculated values of $\mathrm{NBO} /$ $\mathrm{T}$, based on non-tetrahedral coordination of ferrous iron, are 1.5 and 2.8, respectively. From these values of $\mathrm{NBO} / \mathrm{T}$ it is apparent that the observed viscosity decrease during the reduction of acmite and NS4F40 melts is accompanied by depolymerization of the melts.

Figure 7 illustrates the calculated value of $\mathrm{NBO} / \mathrm{T}$ as a function of $\mathrm{Fe}^{3+} / 2 \mathrm{Fe}$ content for NS4F40 melt. The line labelled $\mathrm{Fe}$ (IV) refers to the variation of $\mathrm{NBO} / \mathrm{T}$ as a function of $\mathrm{Fe}^{3+} / \Sigma \mathrm{Fe}$ assuming that all ferric iron is in tetrahedral coordination. The Fe (IV) line is slightly concave downward. The curvature and results from the fact that the reduction of tetrahedral ferric iron to non-tetrahedral ferrous iron decreases the number of tetrahedral ( $T$ ) cations. If the ferric iron were coordinated as a network modifier then the trend of $\mathrm{NBO} / \mathrm{T}$ versus $\mathrm{Fe}^{3+} / \Sigma \mathrm{Fe}$ would be different, as shown by the line labelled Fe (VI) in Fig. 7. The oxidation state-polymerization systematics of Fig. 7 may be qualitatively applied to acmite as well. Figure 7 illustrates that if all ferric iron is non-tetrahedrally coordinated then NS4F40 (and acmite) melt would actually polymerize with reduction. This latter trend results from a decrease in the number of non-bridging oxygens as oxygen is removed from the melt. Table 3 contains the NBO/T values for NS4F40 melts that have been derived from the oxidation state and coordination of ferric and ferrous iron in these samples. The resulting relationship between oxidation state (expressed as $\mathrm{Fe}^{3+}$ /

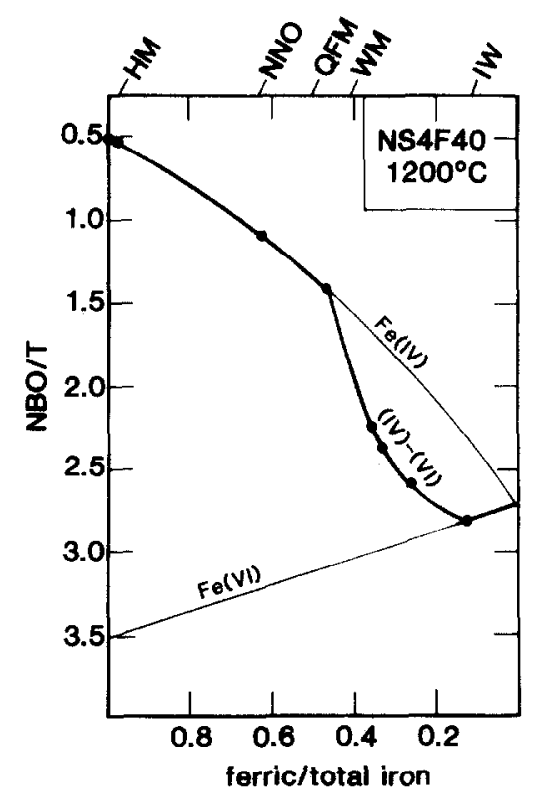

FiG. 7. Polymerization systematics for NS4F40 melt as a function of $\mathrm{Fe}^{3+} / 2 \mathrm{Fe}$. The curves labelled $\mathrm{Fe}$ (IV) and $\mathrm{Fe}$ (VI) refer to the polymerization of melts containing ferric iron exclusively in tetrahedral and non-tetrahedral coordination, respectively: as a function of oxidation state. The heavy line defined by the data points is the trend of calculated NBO/T for NS4F40 melt derived from both viscometry and loop fusion samples. The $\mathrm{fO}_{2}$ calibration from Fig. 5 has been used in Fig. 7 to locate the positions of the haematite-magnetite (HM), nickel-nickel oxide (NNO), quartz-fayalite-magnetite $(\mathrm{QPM})$, wustite-magnetite (WM) and iron-wustite (IW) oxygen fugacity buffers. 
$\Sigma \mathrm{Fe}$ ) and polymerization (expressed as NBO/T) is presented in Fig. 7 as the heavy line defined by the data points. In general, the NS4F40 melt depolymerizes with reduction over the range of $\mathrm{Fe}^{3+} / 2 \mathrm{Fe}$ contents of 1.0 to approximately 0.1 . The depolymerization of oxidized melts occurs along the $\mathrm{Fe}$ (IV) trend but at an intermediate oxidation state $\left(\mathrm{Fe}^{3+} / \mathrm{\Sigma Fe} \approx 0.45\right)$ the coordination of ferric iron becomes dependent on the oxidation state. The transfer of ferric iron from tetrahedral to non-tetrahedral coordination accelerates the depolymerization of the NS4F40 melt with further reduction. The resulting departure of the observed polymerization of NS4F40 from the Fe (IV) trend proceeds to completion (i.e., all ferric iron in non-tetrahedral coordination) before the melt is fully reduced. As a result of this completion the most reduced data point of Fig. 7 represents a melt composition of minimum polymerization along this redox join. Although conditions more reducing that those of this data point were not obtained in the present study, the Fe (VI) trend of Fig. 7, which the melt is constrained to follow with further reduction, should result in polymerization. From the above analysis of Fig. 7, it can be concluded that a minimum in the degree of polymerization should be observable for any silicate melt that follows the trend of iron coordination, as a function of oxidation state, that is described above.

\section{Viscosity-polymerization systematics}

The NBO/T values of Fig. 7 may be compared with the viscosity data of Fig. 3 for any oxidation state. In Fig. 8, the viscosity data are plotted as a function of polymerization $(\mathrm{NBO} / \mathrm{T})$. The data were selected from Figs. 3 and 7 at $\mathrm{Fe}^{3+} / \Sigma \mathrm{Fe}$ contents of $1.0,0.8,0.6,0.4$ and 0.3 . A large negative deviation of melt viscosity from a linear correlation versus melt polymerization (expressed as NBO/T) is illustrated in Fig. 8. Similarly, the binary anorthite-diopside and albite-diopside joins span a large range of $\mathrm{NBO} / \mathrm{T}$ values ( 0 to 2 ) and also exhibit negative deviations of viscosity from a linear correlation with NBO/T (SCARFE et al., 1983; SCARFE and CRONIN, 1986). Such deviations may be due to one or more aspects of the structure or viscous flow mechanism of melts in these systems. In the case of iron-bearing melts, MYSEN et al. (1985a) have suggested that iron redox equilibria affects the relative proportions of silicate polyanionic units by participating in reactions between such units. If reactions involving polyanionic units are a significant factor influencing melt viscosity the fact that such reactions may occur without producing variations in bulk NBO/T (NBO/T-conservative reactions) (MYSEN et al., 1985d) could explain variations of viscosity independent of NBO/T (e.g., DINGWELL, 1986a).

Alternatively, the configurational entropy theory of ADAM and GIBBS (1965) predicts that a negative deviation from additivity of viscosities on a binary join should result simply from the entropy of mixing of the endmembers, and such behavior can translate into a

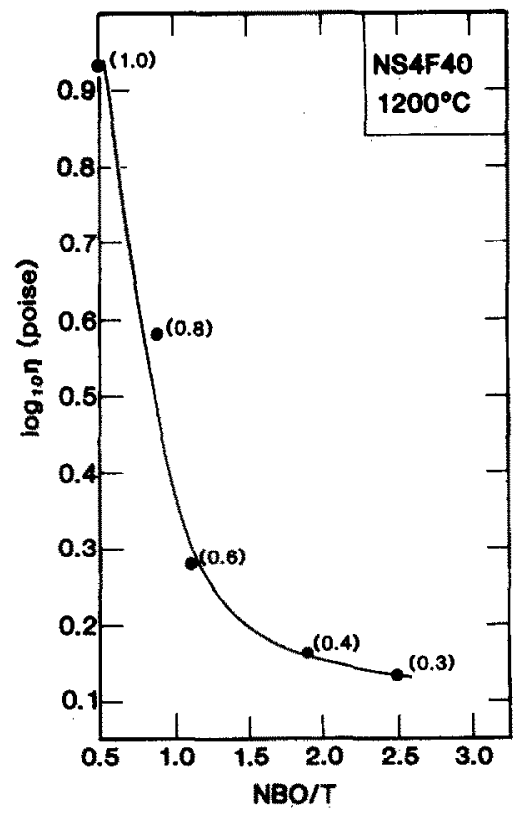

FiG. 8. The relationship between viscosity and polymerization in NS4F40 melt. (Data derived from Figs. 3 and 7.) A large negative deviation from linearity is observed for viscosity.

negative deviation from linearity for the corresponding viscosity-NBO/T relationship. It is important to note that the viscosity-NBO/T relationship may not always be apparent from the viscosity-composition relationship. Viscosities at 1400 to $1600^{\circ} \mathrm{C}$ in the system anorthite-diopside exhibit an additive relationship when plotted versus mole fraction of $\mathrm{Al}_{2} \mathrm{O}_{3}$ (or anorthite) (SCARFE et al., 1983), but when the data are transformed into viscosity-NBO/T space the negative deviation of the viscosity-NBO/T relationship from linearity is apparent.

BREARLEY et al. (1986) have successfully modelled the deviation of viscosity from additivity along the albite-diopside join in terms of the ADAM and GIBBS (1965) theory. In the absence of viscosity data for the ferrous endmembers of the redox joins studied in this investigation, the deviation of viscosity from additivity cannot be quantified and the question of its origin remains open. Regardless, however, of the explanation for the non-linear relationship between melt polymerization and melt viscosity, it is clear from Fig. 8 and from other relatively simple systems such as albite$\mathrm{Na}_{2} \mathrm{O}$ and albite- $\mathrm{F}_{2} \mathrm{O}_{-1}$ (DINGWELL, 1986a,b) that the relationship between NBO/T and viscosity is generally non-linear. Thus, the present authors caution against the use of bulk viscosity as a linear measure of the polymerization of simple silicate melt systems.

\section{CONCLUSIONS}

The present study has shown that the effect of decreasing the $\mathrm{Fe}^{3+} / 2 \mathrm{Fe}$ value of oxidized melts of the system $\mathrm{Na}_{2} \mathrm{O}-\mathrm{FeO}-\mathrm{Fe}_{2} \mathrm{O}_{3}-\mathrm{SiO}_{2}$ is to reduce melt viscosity. The viscosity decrease is large (a factor of 6.5 
at $1200^{\circ} \mathrm{C}$ for NS4F40). The strongly non-linear character of the dependence of viscosity on $\mathrm{Fe}^{3+} / \Sigma \mathrm{Fe}$ results in a region of intermediate $\mathrm{Fe}^{3+} / \Sigma \mathrm{Fe}$ content for the acmite and NS4F40 mclts where viscosity is essentially invariant with respect to $\mathrm{Fe}^{3+} / \Sigma \mathrm{Fe}$.

The ${ }^{57} \mathrm{Fe}$ Mössbauer spectra of quenched melt samples indicate that ferrous iron is a network modifier in these melts, whereas ferric iron is a network former at high $f \mathrm{O}_{2}$ and a network modifier at low $f \mathrm{O}_{2}$. The transition of ferric iron from tetrahedral to non-tetrahedral coordination with decreasing $\mathrm{Fe}^{3+} / \Sigma \mathrm{Fe}$ results in a minimum in calculated bulk polymerization on these compositional (redox) joins. This polymerization minimum corresponds closely to the region of invariant viscosity. If a positive correlation between viscosity and polymerization exists for all oxidation states in these melt compositions then a viscosity increase is predicted for extremely reduced samples.

It is concluded that the viscosity of Fe-rich igneous melts may be significantly influenced by oxidation state and that ferric iron and ferrous iron should be treated as separate components in calculation schemes for estimating the viscosities of natural silicate liquids. Before quantitative extrapolation of these results to natural melts is attempted, however, several aspects of the viscosity of iron-bearing silicate melts require investigation. Firstly, the temperature-dependence of ironbearing silicate melts must be determined as a function of oxidation state. Secondly, the effect of replacing $\mathrm{Na}$ with other mono- and divalent cations (e.g., $\mathrm{Ca}, \mathrm{Mg}$, $\mathrm{K})$ must be evaluated. Thirdly, the effect of aluminum on the viscosities of simple, iron-bearing silicate melts must be determined. Work is in progress to evaluate each of these factors in order that a general model of the effect of oxidation state on viscosity may be applied to natural magmas.

Acknowledgements-We wish to thank Bob Luth for his comments and Mark Brearley and Jim Dickinson for their reviews. We also wish to thank Hatten S. Yoder, Jr. for his support and encouragement.

\section{Editorial handling: P. C. Hess}

\section{REFERENCES}

ADAM G. and GIBBS J. H. (1965) On the temperature dependence of cooperative relaxation properties in glass-forming liquids. J. Chem. Phys. 43, 139-146.

BOTTINGA Y. and WEILL D. F. (1972) The viscosity of magmatic silicate liquids: a model for calculation. Amer. J. Sci. 272, 438-475.

BREaRley M., Dickinson J. E. and SCaRfE C. M. (1986) Pressure dependence of melt viscosities on the join diopsidealbite. Geochim. Cosmochim. Acta 50, 2563-2570.

Brown G., KEEFER K. D. and FENN P. M. (1979) Extended X-ray absorption fine structure (EXAFS) study of ironbearing silicate glasses: iron coordination environment and oxidation state. (abstr.) Geol. Soc. Amer. Abstr. Prog. 11, 373.

Cukierman M., TUtTS P. M. and UHLMaNN D. R. (1972) Viscous flow behavior of lunar compositions 14259 and 14310. Proc. Lunar Sci. Conf. 3rd, 2619-2625.

CUKIERMAN M. and UHLMANN D. R. (1974) Effects of iron oxidation state on viscosity, Lunar composition $15555 . J$. Geophys. Res. 79, 1594-1598.

DANCKWERTH P. A. (1982) The nature of basic cation coordination in silicate glass: evidence from Mössbauer spectroscopy. Carnegie Inst. Wash. Yearb. 81, 340-342.

DANCKWERTH P. A. and VIRGO D. (1982) Structural state of iron in the system $\mathrm{Na}_{2} \mathrm{O}-\mathrm{SiO}_{2}-\mathrm{Fe}-\mathrm{O}$. Carnegie Inst. Wash. Yearb. 81, 340-342.

DINGWELL D. B. (1986a) Viscosity-temperature relationships in the system $\mathrm{Na}_{2} \mathrm{Si}_{2} \mathrm{O}_{5}-\mathrm{Na}_{4} \mathrm{Al}_{2} \mathrm{O}_{5}$. Geochim. Cosmochim. Acta 50, 1261-1265.

DINGWELL D. B. (1986b) Melt viscosities in the system albite$\mathrm{H}_{2} \mathrm{O}_{-} \mathrm{F}_{2} \mathrm{O}_{-1}$. In Magmatic Processes: Physicochemical Principles (ed. B. O. MYSEN) The Geochemical Society, Spec. Publ. No. 1 (in press).

DINGWELL D. B. and VIRGo D. (1986) Viscosity, redox equilibria and the coordination of ferric iron in silicate melts. (abstr.) Geol. Soc. Amer. Abstr. Prog. 18 (in press).

DYAR, M. D. (1985) A review of Mössbauer data on inorganic glasses: the effects of composition on iron valency and coordination. Amer. Mineral. 70, 304-316.

EIBSCHUTZ M., LINES M. E. and NASSAU K. (1980) Electricfield-gradient in vitreous yittrium iron garnet. Phys. Rev. B21, 3767-3770.

FoX K. E., FuruKaWA T. and WhITE W. B. (1982) Transition metal ions in silicate melts. Part 2, Iron in sodium silicate glasses. Phys. Chem. Glasses 23, 169-178.

GoldMAN D. S. (1983) Oxidation equilibrium of iron in borosilicate glass. J. Amer. Cer. Soc. 66, 205-209.

GOLDMAN D. S. (1986) Evaluation of the ratios of bridging to nonbridging oxygens in simple silicate glasses by electron spectroscopy for chemical analysis. Phys. Chem. Glasses $27,128-133$.

GoldMAN D. S. and BEwLEY D. E. (1985) Ferrous/ferric Mössbauer analysis of simulated nuclear waste glass with and without computer fitting. J. Amer. Cer. Soc. 12, 691695.

Goldman D. S., BRite D. W. and Richey W. C. (1986) Investigation of foaming in liquid-fed melting of simulated nuclear waste glass. J. Amer. Cer. Soc. 69, 413-417.

Henderson G. S., Fleet M. S. and Bancroft G. M. (1984) An X-ray scattering study of vitreous $\mathrm{KFeSi}_{3} \mathrm{O}_{8}$ and $\mathrm{NaFeSi}_{3} \mathrm{O}_{8}$ and reinvestigation of vitreous $\mathrm{SiO}_{2}$ using quasicrystalline modelling. J. Non-Cryst. Sol. 68, 333-349.

JOHANNSEN F. and BRUNION H. (1959) Untersuchungen zur Viskosität von Rennschlaken. Zeitschr. Erzbergbau und Metallhuttenwesen 12, 21-219, 272-279.

KLein L. C., Fasano B. V. and WU J. M. (1983) Viscous flow behavior of four iron-containing silicates with alumina, effects of composition and oxidation condition. Proc. Lunar Planet. Sci. Conf. 13th; J. Geophys. Res. 88, A880-A886.

KozAKEVITCH P. (1949) Tension superficielle et viscosité des scories synthétiques. Rev. Metall. 46, 505-516, 572-582.

LILLIE H. R. (1931) Viscosity of glass between the strain point and melting temperature. J. Amer. Cer. Soc. 14, 502-511.

MaO H. K., VIRGo D. and Bell P. M. (1973) Analytical study of the orange lunar soil returned by the Apollo 17 astronauts. Carnegie Inst. Wash. Yearb. 72, 631-638.

MASSIOT D. (1985) Shape comparison of physical spectra: application to Mössbauer spectra of silicate glasses. J. NonCryst. Sol. 69, 371-380.

Mo X., Carmichael I. S. E., Rivers M. and Stebbins J. (1982) The partial molar volume of $\mathrm{Fe}_{2} \mathrm{O}_{3}$ in multicomponent silicate liquids and the pressure dependence of oxygen fugacity in magmas. Mineral. Mag. 45, 237-245.

MYSEN B. O. (1986) Relations between structure, redox equilibria of iron and properties of magmatic liquids. In $A d$ vances in Physical Geochemistry (eds. I. KUSHIRO and L. PERCHUK) (in press).

MYSEN B. O., VIRGO D. and SEIFERT F. (1982) The structure of silicate melts: implications for chemical and physical properties of natural magmas. Rev. Geophys. Sp. Phys. 20, 353-383. 
MYSEN B. 0, VIRGO D. and SEIFERT F. A. (1984) Redox equilibria of iron in alkaline earth silicate melts: relationships between melt structure, oxygen fugacity, temperature and properties of iron-bearing silicate liquids. Amer. Mineral. 69, 834-847.

Mysen B. O., Virgo D., Neumann E. and Seifert F. A. (1985a) Redox equilibria and the structural states of ferric and ferrous iron in melts in the system $\mathrm{CaO}-\mathrm{MgO}-\mathrm{Al}_{2} \mathrm{O}_{3}$ $\mathrm{SiO}_{2}-\mathrm{Fe}-\mathrm{O}$ : relationships between redox equilibria, melt structure and liquidus phase equilibria. Amer. Mineral. 70 , 317-331.

MYSEN B. O., ViRgo D., SCARFE C. M. and CRONIN D. J. (1985b) Viscosity and structure of iron- and aluminumbearing calcium silicate melts at 1 atm. Amer. Mineral. 70, 487-498.

MYSEN B. O., CARMICHAEL I. S. E. and VIRGO D. (1985c) A comparison of iron redox ratios in silicate glasses determined by wet-chemical and ${ }^{57} \mathrm{Fe}$ Mössbauer resonant absorption methods. Contrib. Mineral. Petrol. 90, 101-106.

MYSEN B. O., Virgo D. and SeIfERT F. A. (1985d) Relationships between properties and structure of aluminosilicate melts. Amer. Mineral. 70, 88-105.

PAUL A and Douglas R. W. (1965) Ferrous-ferric equilibrium in binary alkali silicate glasses. Phys. Chem. Glasses 6, 207-211.

RONTGEN P., WINTERHAGER H. and KAMMEL R. (1960) Struktur und Eigenschaften von Schlaken der Metallhuttenprozesse. II. Viskositätsmessungen an Schmelzen der Systeme Eisenoxydul-Kalk-Kieselsaure und EisenoxydulKalk-Tonerde-Kieselsaure. Zeitschr. fiir Erzbergbau und Metallhuttenwesen 8, 363-373.

SCARFE C. M. and CRONIN D. J. (1986) Viscosity-temperature relationships of melts at l-atm in the system diopside-albite. Amer. Mineral. 71, 767-771. SCAREEC. M, CRONND.J, WENTZEL J, T, and KaUfFMAN D. A. (1983) Viscosity-temperature relationships at 1 atm in the system diopside-anorthite. Amer. Mineral. 68, 10831088.

SEKI K. and OETERS F. (1984) Viscosity measurements on liquid slags in the system $\mathrm{CaO}-\mathrm{FeO}-\mathrm{Fe}_{2} \mathrm{O}_{3}-\mathrm{SiO}_{2}$. Trans. Iron Steel Inst. Jap. 24, 445-454.

SHIMIZU N. and KUSHIRO I. (1984) Diffusivity of oxygen in jadeite and diopside melts at high pressures. Geochim. Cosmochim. Acta 48, 1295-1303.

SPIERING B. and SEIFERT F. A. (1985) Iron in silicate glasses of granitic composition: a Mössbauer spectroscopic study. Contrib. Mineral. Petrol. 90, 63-73.

TogurI J. M., KaIURA G. H. and Marchant G. (1976) The viscosity of molten $\mathrm{FeO}-\mathrm{Fe}_{2} \mathrm{O}_{3}-\mathrm{SiO}_{2}$ system. In Extraction Metallurgy of Copper. I. Physical Chemistry of Copper Smelting, pp. 259-273. Metall. Soc. of AIME, New York.

TOOP G. W. and SAMIS C. S. (1962) Activities of ions in silicate melts. Trans. Metall. Soc. AIME 227, 492-500.

VIRGO D. and MYSEN B. O. (1985) The structural state of iron in oxidized versus reduced glasses at 1 atm: a ${ }^{57} \mathrm{Fe}$ Mössbauer study. Phys. Chem. Mineral. 12, 65-76.

Williamson J., TIPPLE A. J. and RoGers P. S. (1968) Influence of iron oxides on kinetics of crystal growth in $\mathrm{CaO}$ $\mathrm{MgO}-\mathrm{Al}_{2} \mathrm{O}_{3}-\mathrm{SiO}_{2}$ glasses. J. Iron Steel Inst. London 206 , 898-903.

WIVEL C. and MORUP S. (1981) Improved computational procedure for evaluation or overlapping hyperfine parameter distributions in Mössbauer spectra. J. Phys. E. Sci. Instrum. 14, 605-610. 